\title{
Mathematical modelling of wet oxidation of excess sludge
}

\author{
Andrzej Chacuk, Mirosław Imbierowicz
}

Technical University of Łódź, Faculty of Process and Environmental Engineering, 90-924 Łódź, ul Wólczańska 213, Poland, e-mail: chacuk@wipos.p.lodz.pl, fax: +48426368133

\begin{abstract}
A mathematical model enabling a quantitative description of wet oxidation of excess sludge in continuous bubble columns is proposed. The model consists of mass and heat transfer kinetic equations and material and heat balance equations of gas and liquid phases flowing through the absorber. The equations of material and heat balance refer to a parallel, co- current flow of gas and liquid phase and take into account a complex chemical reaction in the liquid phase core. The proposed model was used in a numerical simulation of wet oxidation in a bubble absorber for different process conditions: flow rate and composition of the gas and liquid phase, temperature and pressure, and different heights and diameters of the column.
\end{abstract}

Keywords: mathematical modelling, wet oxidation, excess sludge, bubble column.

Presented at VII Conference Wasteless Technologies and Waste Management in Chemical Industry and Agriculture, Międzyzdroje, 12 - 15 June, 2007.

\section{INTRODUCTION}

Management of sludge generated in wastewater treatment plants is a serious problem in Poland. Due to strict legal regulations, the role of „classical” techniques for the utilisation of this sludge such as e.g. storage, composting and agricultural use, is continually decreasing. In this situation, the importance of thermal processing of this type of waste increases because these techniques have many advantages: high efficiency, a possibility of energy recovery from biomass, and are preferable excess sludge utilisation methods in the European Union.

Wet oxidation is one of the techniques of thermal utilisation of excess sludge and consists in oxidation of biomass by oxygen in a liquid phase, under increased pressure (0.2 to $10 \mathrm{MPa}$ ) and at elevated temperature $(393-573 \mathrm{~K})$. The process is characterised by high efficiency because it enables over $80 \%$ reduction of TOC in the suspension and complete dissolution of biomass which forms a solid phase of the sludge ${ }^{1}$. Owing to the important role of wet oxidation in industry ${ }^{2-4}$, mathematical models that provide a relatively precise quantitative description of the process, become also important. The models can be used both in designing industrial absorbers for wet oxidation, and in determining new process conditions that enable improvement of the already existing absorbers. In this study, a mathematical model is proposed to describe quantitatively the process of wet oxidation of excess sludge in continuous absorbers.

\section{CHEMICAL REACTION}

Wet oxidation of organic compounds is a complex reaction whose mechanism is not fully known ${ }^{5,6}$. In this study, a sequence of reactions taking place in the system was approximated by four non-elementary chemical reactions ${ }^{6}$ :

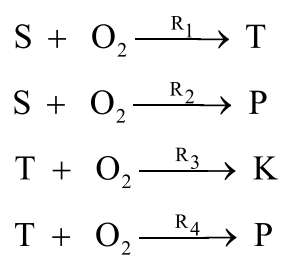

where: $\mathrm{S}$ - activated sludge; $\mathrm{T}$ - readily oxidable organic compounds; $\mathrm{K}$ - sparingly oxidable carboxylic acids; $\mathrm{P}$ products of oxidation (carbon dioxide, water, etc.).

The partial reaction rates are described by the relations:

$\mathrm{R}_{\mathrm{j}}=\mathrm{k}_{\mathrm{j}} \mathrm{C}_{1 \mathrm{~L}}^{\mathrm{a}} \mathrm{C}_{\mathrm{iL}}^{2}, \mathrm{j}=1,2 \Rightarrow \mathrm{i}=5 ; \mathrm{j}=3,4 \Rightarrow \mathrm{i}=6$

$\mathrm{k}_{\mathrm{j}}=\mathrm{k}_{0 \mathrm{j}} \exp \left(-\mathrm{E}_{\mathrm{j}} / \mathrm{RT}\right), \quad \mathrm{j}=1, \ldots, 4$

The subscripts in the concentration symbols $\mathrm{C}$ denote: $1 \equiv \mathrm{O}_{2}, 2 \equiv \mathrm{P}\left(\mathrm{CO}_{2}\right), 3 \equiv \mathrm{H}_{2} \mathrm{O}, 4 \equiv \mathrm{N}_{2}, 5 \equiv \mathrm{S}, 6 \equiv \mathrm{T}, 7 \equiv \mathrm{K}$

Concentrations of compounds $\mathrm{S}, \mathrm{T}$ and $\mathrm{K}$ are expressed as mole of total organic carbon (TOC) per cubic meter.

Values of kinetic parameters and the heats of reaction (1) - (4) are taken from Imbierowicz and Chacuk ${ }^{6}$.

\section{KINETICS OF MASS AND HEAT TRANSFER}

The process of wet oxidation of organic compounds in sludge proceeds in a heterogeneous gas-liquid system, under non-isothermal conditions. A mathematical description of mass and heat transfer ${ }^{7}$ covers (Fig.1):

- mass transfer equations in the gas and liquid phase

$\mathbf{N}_{\mathrm{G}}=\mathrm{C}_{\mathrm{G}} \mathbf{k}_{\mathrm{G}} \boldsymbol{\Xi}_{\mathrm{G}}^{*}\left(\mathbf{y}-\mathbf{y}^{*}\right)+\mathbf{y} \sum_{\mathrm{i}=1}^{3} \mathrm{~N}_{\mathrm{iG}}$

$\mathbf{N}_{\mathrm{L}}=\mathrm{k}_{\mathrm{L}} \boldsymbol{\Xi}_{\mathrm{L}}\left(\mathbf{C}_{\mathrm{L}}^{*}-\mathbf{C}_{\mathrm{L}}\right)+\mathbf{C}_{\mathrm{L}} / \mathrm{C}_{\mathrm{L}} \sum_{\mathrm{i}=1}^{3} \mathrm{~N}_{\mathrm{iL}}$

- heat transfer equations in the gas and liquid phase

$\varepsilon_{\mathrm{G}}=\alpha_{\mathrm{G}}\left(\mathrm{T}_{\mathrm{G}}-\mathrm{T}^{*}\right)+\sum_{\mathrm{i}=1}^{3} \widetilde{\mathrm{H}}_{\mathrm{iG}}^{*} \mathrm{~N}_{\mathrm{iG}}$

$\varepsilon_{\mathrm{L}}=\alpha_{\mathrm{L}}\left(\mathrm{T}^{*}-\mathrm{T}_{\mathrm{L}}\right)+\sum_{\mathrm{i}=1}^{3} \widetilde{\mathrm{H}}_{\mathrm{iL}}^{*} \mathrm{~N}_{\mathrm{iL}}$

- conditions of mass and heat flux continuity on the interface

$\mathbf{N}_{\mathrm{G}}=\mathbf{N}_{\mathrm{G}}^{*}=\mathbf{N}_{\mathrm{L}}^{*}=\mathbf{N}_{\mathrm{L}}^{\delta}=\mathbf{N}_{\mathrm{L}}$

$\varepsilon_{\mathrm{G}}=\varepsilon_{\mathrm{G}}^{\delta}=\varepsilon_{\mathrm{G}}^{*}=\varepsilon_{\mathrm{L}}^{*}=\varepsilon_{\mathrm{L}}^{\delta}=\varepsilon_{\mathrm{L}}$

- thermodynamic equilibrium equations

$\mathrm{f}_{\mathrm{i}}\left(\mathbf{y}^{*}, \mathrm{C}^{*}, \mathrm{~T}^{*}\right)=0, \quad \mathrm{i}=1,2,3$

- determinancy conditions

$\mathrm{N}_{4 \mathrm{G}}=0$ 


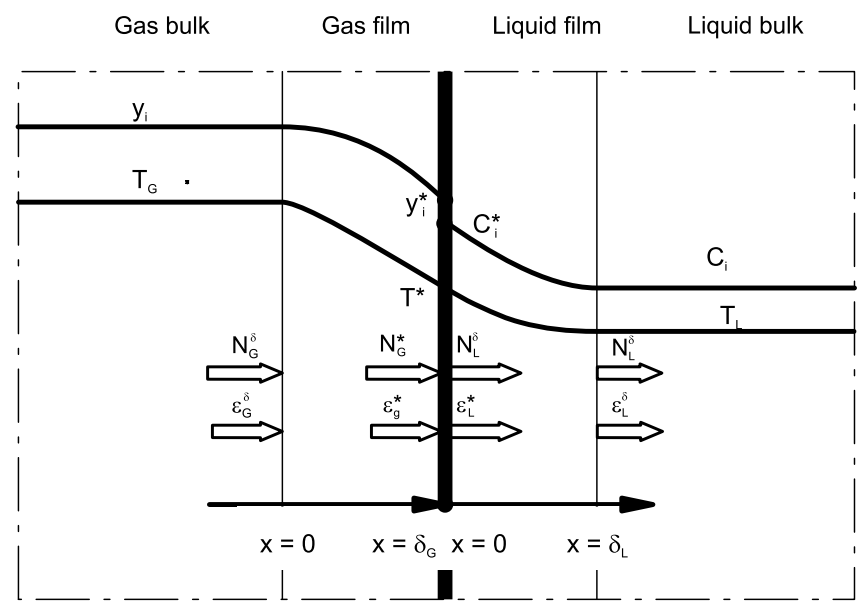

Figure 1. Scheme of mass and heat transfer

For the assumed state of gas and liquid phase cores (composition and temperature), in a given cross section of the column, relations (7) - (14) enable determination of the conditions in the interface, mass streams of particular components and heat flux that are necessary for bubble column balances.

\section{BALANCE EQUATION FOR THE BUBBLE COLUMN}

A mathematical description was formulated under the following assumptions (Fig. 2):

- the process is steady and adiabatic

- the flow of phases corresponds to the model of plug flow with axial dispersion

- the chemical reaction takes place in the liquid phase core only

- the temperatures of liquid core and interfacial area are the same

- the column diameter and total height as well as all parameters of streams flowing to this column are known.

For the assumed kinetic model of the reaction and simplifying assumptions, mass balances for particular reagents and heat balances have the form:

- gas phase

$\frac{\mathrm{d} \mathrm{W}_{\mathrm{iG}}}{\mathrm{dz}}=-\mathrm{a}_{\mathrm{m}} \mathrm{N}_{\mathrm{iG}}, \mathrm{W}_{\mathrm{iG}}(0)=\mathrm{W}_{\mathrm{iG} 0}, \quad \mathrm{i}=1,2,3$

$W_{i G}=-\alpha C_{G} D_{D G} \frac{d y_{i}}{d z}+y_{i} W_{G},\left(\frac{d y_{i}}{d z}\right)_{z=Z}=0, \quad i=1,2,3$

$\mathrm{W}_{\mathrm{G}}=\sum_{\mathrm{i}=1}^{4} \mathrm{~W}_{\mathrm{iG}}, \sum_{\mathrm{i}=1}^{4} \mathrm{y}_{\mathrm{i}}=1$

$\frac{\mathrm{d}\left(\sum_{\mathrm{i}=1}^{4} \widetilde{\mathrm{H}}_{\mathrm{iG}} \mathrm{W}_{\mathrm{iG}}\right)}{\mathrm{dz}}=-\mathrm{a}_{\mathrm{m}} \varepsilon_{\mathrm{G}},\left(\sum_{\mathrm{i}=1}^{4} \widetilde{\mathrm{H}}_{\mathrm{iG}} \mathrm{W}_{\mathrm{iG}}\right)(0)=\left(\sum_{\mathrm{i}=1}^{4} \widetilde{\mathrm{H}}_{\mathrm{iG}} \mathrm{W}_{\mathrm{iG}}\right)_{0}$

- liquid phase

$\frac{d W_{i L}}{d z}=a_{m} N_{i L}+\beta \sum_{j=1}^{4} v_{i, j} R_{j}, \quad W_{i L}(0)=W_{i L 0}, \quad i=1,2$

$\frac{\mathrm{dW}_{3 \mathrm{~L}}}{\mathrm{dz}}=\mathrm{a}_{\mathrm{m}} \mathrm{N}_{3 \mathrm{~L}}$

$\frac{d W_{i+2 L}}{d z}=\sum_{j=1}^{4} v_{i+2, j} R_{j}, \quad W_{i+2 L}(0)=W_{i+2 L 0}, \quad i=3,4,5$

$\mathrm{W}_{\mathrm{iL}}=-\beta \mathrm{D}_{\mathrm{DL}} \frac{\mathrm{d}_{\mathrm{iL}}}{\mathrm{dz}}+\frac{\mathrm{C}_{\mathrm{iL}}}{\mathrm{C}_{\mathrm{L}}} \mathrm{W}_{\mathrm{L}},\left(\frac{\mathrm{dC}_{\mathrm{iL}}}{\mathrm{dz}}\right)_{z=\mathrm{Z}}=0, \mathrm{i}=1, \ldots, 7 ; \mathrm{i} \neq 4$

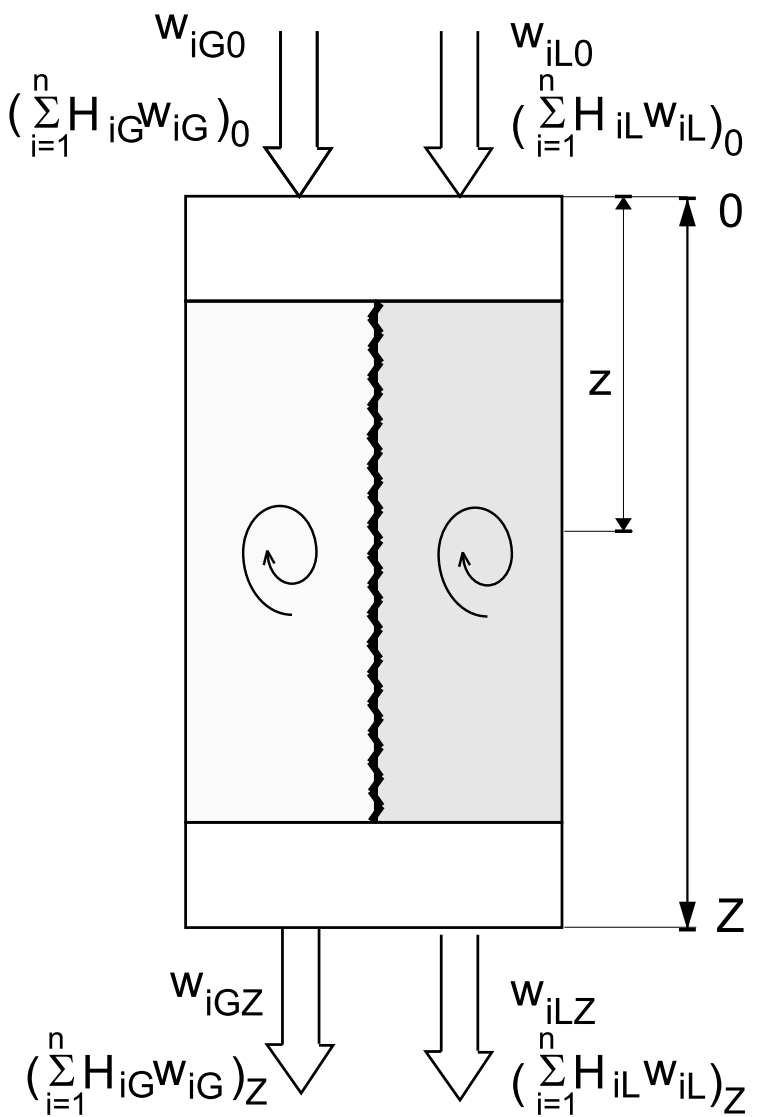

Figure 2. Schematic diagram of bubble columns

$\mathrm{C}_{\mathrm{iL}}=\mathrm{W}_{\mathrm{iL}} / \mathrm{u}_{\mathrm{L}}, \quad \mathrm{i}=1, \ldots, 7 ; \mathrm{i} \neq 4$

$\mathrm{W}_{\mathrm{L}}=\mathrm{V}_{\mathrm{L}} \mathrm{C}_{\mathrm{L}}, \mathrm{u}_{\mathrm{L}}=\mathrm{V}_{\mathrm{L}} / \mathrm{A}_{\mathrm{k}}, \mathrm{C}_{\mathrm{L}}=\rho_{\mathrm{L}} / \mathrm{M}_{\mathrm{L}}$

$\frac{d\left(\sum_{i=1, i \neq 4}^{7} \widetilde{H}_{i L} W_{i L}\right)}{d z}=a_{m} \varepsilon_{L},\left(\sum_{i=1, i \neq 4}^{7} \widetilde{H}_{i L} W_{i L}\right)(0)=\left(\sum_{i=1, i \neq 4}^{7} \widetilde{H}_{i L} W_{i L}\right)_{0}$

For a given bubble column height $\mathrm{Z}$, differential equations (15) - (25), along with appropriate boundary conditions (Fig. 2), constitute a mathematical description of wet oxidation of excess sludge in the column. For the dispersive flow, boundary conditions of the model are determined in two extreme column cross sections $(\mathrm{O}$ and $\mathrm{Z}$ ). For this reason differential equations constitute a twopoint boundary condition. In this study, the problem was solved using a simple shooting method ${ }^{7}$. Differential equations, due to their rigidity, were integrated using an semiimplicit third order Runge-Kutta method ${ }^{8}$.

\section{NUMERICAL SIMULATION}

In order to test the proposed mathematical model, a numerical simulation of wet oxidation of excess sludge in a co- and counter-current bubble column for different process parameters and various sizes of the apparatus was carried out. The results of calculations presented in this paper refer to the process carried out under pressure $\mathrm{P}=$ $6 \mathrm{MPa}$ in the co-current bubble column of diameter $\mathrm{d}_{\mathrm{k}}=$ $1 \mathrm{~m}$ and height $\mathrm{Z}=10 \mathrm{~m}$ for the parameters of gas and liquid phase streams being:

-gas phase: temperature $\mathrm{T}_{\mathrm{G} 0}=473.15 \mathrm{~K}$, volumetric flow rate $\mathrm{v}_{\mathrm{G} 0}=0.04 \mathrm{~m}^{3} / \mathrm{s}$, molar fraction of oxygen and nitrogen: $\mathrm{y}_{10}=0.5$ and $\mathrm{y}_{40}=0.5$, respectively; 


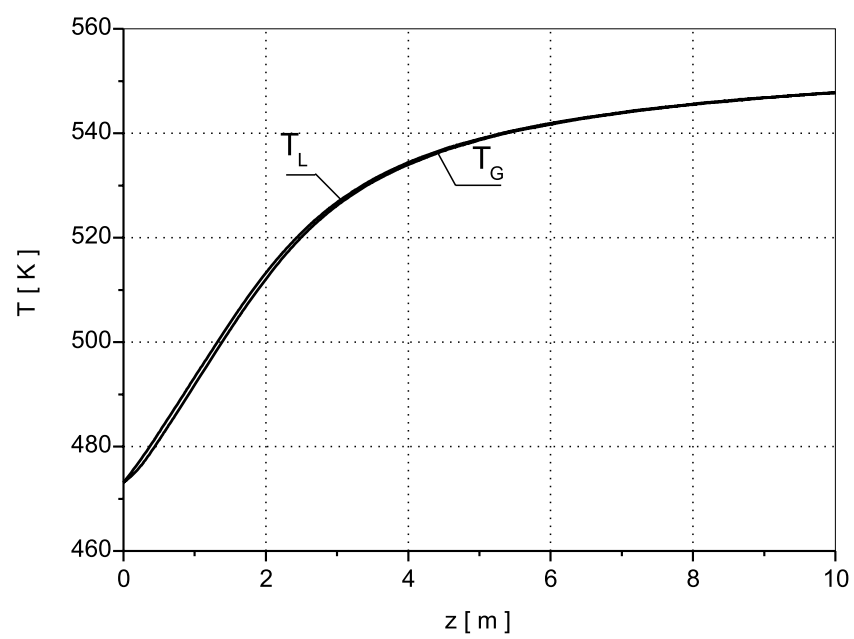

Figure 3. Temperature profiles in the bubble column $\mathrm{G}$ gas phase, $\mathrm{L}$ - liquid phase

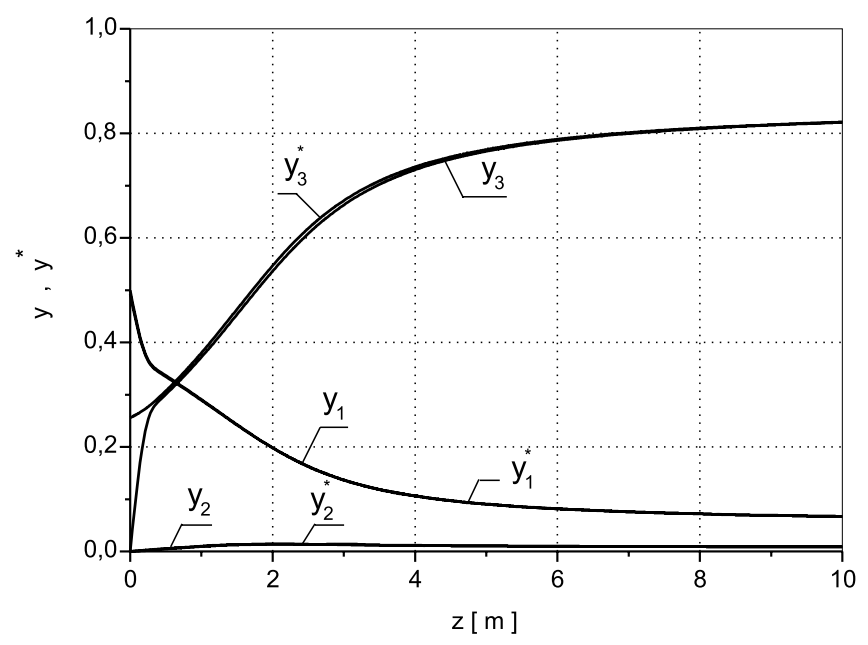

Figure 4. Composition profiles in the bubble column $1 \equiv \mathrm{O}_{2}, 2 \equiv \mathrm{P}\left(\mathrm{CO}_{2}\right), 3 \equiv \mathrm{H}_{2} \mathrm{O}$

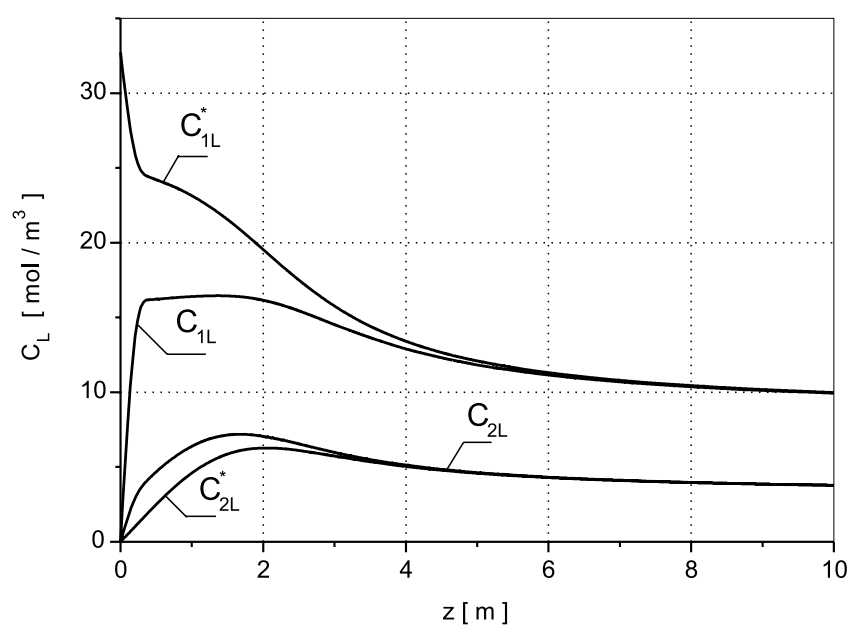

Figure 5. Composition profiles of $\mathrm{O}_{2}$ and $\mathrm{P}\left(\mathrm{CO}_{2}\right)$ in the bubble column $1 \equiv \mathrm{O}_{2}, 2 \equiv \mathrm{P}\left(\mathrm{CO}_{2}\right)$

- liquid phase: temperature $\mathrm{T}_{\mathrm{L} 0}=473.15 \mathrm{~K}$, volumetric flow rate $\mathrm{v}_{\mathrm{L} 0}=0.005 \mathrm{~m}^{3} / \mathrm{s}$, composition: $\mathrm{C}_{5 \mathrm{~L} 0}=0.36$ $\mathrm{kmol} / \mathrm{m}^{3}, \mathrm{C}_{6 \mathrm{~L} 0}=\mathrm{C}_{7 \mathrm{~L} 0}=0 \mathrm{kmol} / \mathrm{m}^{3}$.

The results of numerical calculations are given in Figures 3 to 6 .

The wet oxidation of excess sludge is a strongly exothermal process, so the temperature of both liquid and gas phase grows very quickly along the column height

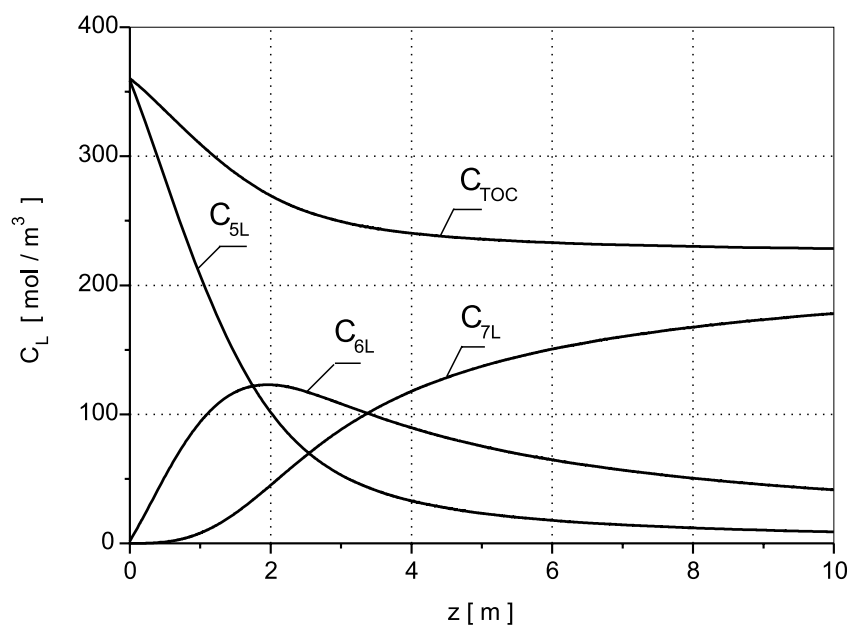

Figure 6. Composition profiles of $\mathrm{S}, \mathrm{T}, \mathrm{K}$ and global TOC in the bubble column $5 \equiv \mathrm{S}, 6 \equiv \mathrm{T}, 7 \equiv \mathrm{K}$

(Fig. 3). The mass flow resistance of oxygen and carbon dioxide in the gas phase has no significant effect on the process rate, while the effect of mass transfer resistance of water vapour is revealed on a very short segment of the column only (Fig. 4). The mass transfer resistance in the liquid phase is significant, particularly in reference to oxygen (Fig. 5). The concentration of readily oxidable compounds $(\mathrm{T})$ in the column reaches maximum (Fig. 6), because these are intermediate compounds of the reaction (1) - (4). The concentration of total organic carbon $\mathrm{C}_{\mathrm{TOC}}$ (the sum of concentrations of compounds $\mathrm{S}, \mathrm{T}$ and $\mathrm{K}$ ) decreases along the column height, but its decrease is much milder than the drop of excess sludge concentration (Fig. 6).

\section{CONCLUSIONS}

Irrespective of process conditions of wet oxidation, direction of phase flow or column size, the numerical calculations show that the resistance of mass transfer of oxygen and carbon dioxide in the gas phase has no significant influence on the process rate. The effect of mass transfer resistance of water vapour in this phase is insignificant and is revealed on a very short segment of the column only. However, the mass transfer resistance is vital in the liquid phase, particularly in reference to oxygen. Heat transfer resistance in the gas phase is negligibly small. The direction of phase flow has no practical influence on the degree of excess activated sludge conversion and total organic carbon concentration in the stream of liquid leaving the column.

\section{NOMENCLATURE}

a - index,

$\mathrm{a}_{\mathrm{m}} \quad$ - interfacial area, $\mathrm{m}^{2} / \mathrm{m}^{3}$

$\mathrm{d}_{\mathrm{k}} \quad$ - column diameter, $\mathrm{m}$

C - molar concentration, $\mathrm{kmol} / \mathrm{m}^{3}$

$\mathrm{C}_{\mathrm{L}}$ - vector of molar concentration, $\mathrm{kmol} / \mathrm{m}^{3}$

$\mathrm{D}_{\mathrm{D}}$ - dispersion coefficient, $\mathrm{m} / \mathrm{s}$

$\mathrm{E}$ - activation energy, $\mathrm{kJ} / \mathrm{mol}$

$\mathrm{k}-$ - mass transfer coefficient, $\mathrm{m} / \mathrm{s}$

$\mathrm{k} \quad$ - chemical reaction rate constant, $\mathrm{m}^{3 \mathrm{a}} /\left(\mathrm{kmol}^{\mathrm{a}} \cdot \mathrm{s}\right)$

k - matrix of multi-component mass transfer coeffi cient, $\mathrm{m} / \mathrm{s}$

$\mathrm{H} \quad$ - molar enthalpy, $\mathrm{kJ} / \mathrm{mol}$ 


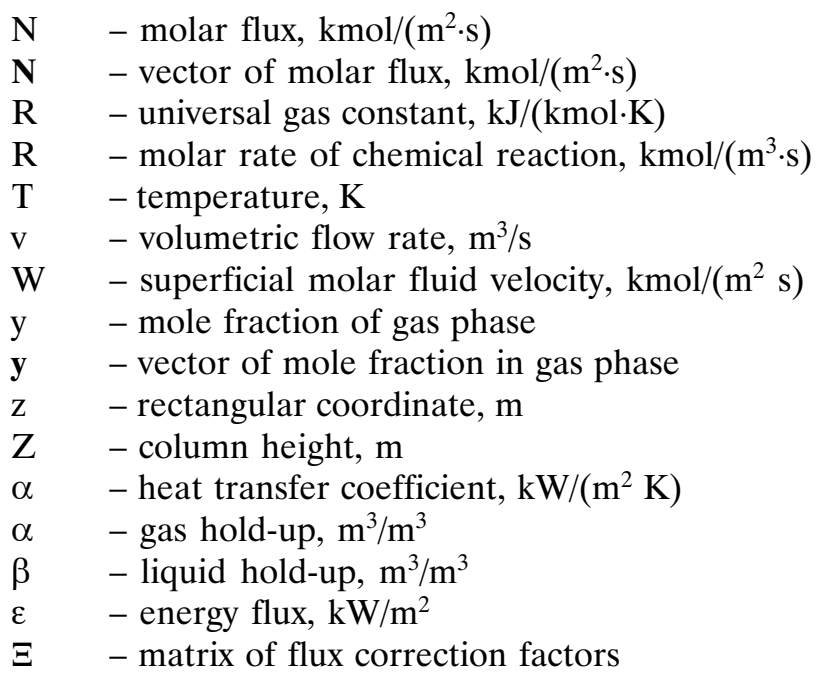

\section{SUBSCRIPTS}

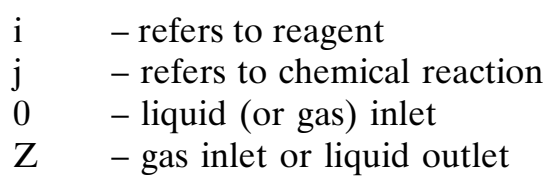

\section{SUPERSCRIPTS}

i $\quad-$ in the bulk of fluid

* - gas-liquid interface

$\sim$ - partial value

\section{LITERATURE CITED}

(1) Bhargava S. K., Tardio J., Prasad J., Foger K., Akolekar D. B., Grocott S. C.: Wet oxidation and catalytic wet oxidation, Ind. Eng. Chem. Res., 2006, 45, 1221.

(2) Kolaczkowski S. T., Plucinski P., Beltran F. J., Rivas F. J., McLurgh D. B.: Wet air oxidation: a review of process technologies and aspects in reactor design., Chem. Eng. J., 1999, 73(2), 1999.

(3) Debellefontaine H., Foussard J. N.: Wet air oxidation for the treatment of industrial wastes. Chemical aspects, reactor design and industrial applications in Europe, Waste Management, 2000, 20, 15.

(4) Bień J. B.: Osady ściekowe - teoria i praktyka, Politechnika Częstochowska, 2002.

(5) Tettamanti M., Lasagni M., Collina E., Sancassani M., Pitea D., Fermo P., Fariati F.: Thermal Oxidation Kinetics and Mechanism of Sludge from a Wastewater Treatment Plant, Environ. Sci. Technol., 2001, 35, 3981.

(6) Imbierowicz M., Chacuk A.: The advanced kinetic model of the excess activated sludge wet oxidation, Pol. J. Chem. Tech., 2006, 8(2), 16.

(7) Zarzycki R., Chacuk A.: Absorption: Fundamentals \& Applications, Pergamon Press, Oxford, 1993.

(8) Michelsen M. L.: An efficient general purpose method for the integration of stiff ordinary differential equations, AIChE J., 1976, 22(3), 594. 